\title{
Emerging Technologies Integral Estimation Dynamic Model of the Company Financial Risks
}

\author{
Yakupova N. M. ${ }^{1}$, Kadochnikova E.I. ${ }^{2}$, Rafikova A. V. ${ }^{3}$, Vasily I. Eremin ${ }^{4}$ \\ ${ }^{1,2,3}$ Kazan Federal University, Russia. \\ ${ }^{4}$ Doctor of Economic Sciences, Professor, Russian State Agrarian University named after K.A. Timiryazev, \\ Russian Federation, 127550, Moscow, Timiryazevskaya street, 49.
}

\begin{abstract}
The authors proposed and tested an integrated assessment dynamic model of enterprise financial risks to evaluate the investment attractiveness of the enterprise. The study draws attention to the fact that the dynamic assessment of enterprise financial risks based on applied statistical analysis systematized a wide variety of financial indicators, gave a visual representation of economic information as a result of the connection ordinal measurement between dynamically ordered indicators in accordance with the identified preference ratios. The results of structural and dynamic assessment of the enterprise financial risk level presented in the article showed high volatility of financial risk for investors. The results of testing the integrated assessment dynamic model of enterprise financial risks confirmed the feasibility of its practical use by both owners and investors to assess the risks of investing in the enterprise.
\end{abstract}

Keywords: financial risk, Kendall rank correlation, investment attractiveness, net profit.

\section{INTRODUCTION}

The system compliance degree (investment object) with the investor interests (investment subject) by reflecting the set of typical motivations and interests of the potential investors on the open market in a competitive environment reflects the investment attractiveness of the enterprise [1]. We agree that due to insufficient research of the "investment attractiveness of the enterprise" category at the moment there is no unified methodology for its assessment and, as a result, approaches to generalizing economic indicators that characterize the internal environment of the enterprise. In other countries, the model of the bankruptcy probability index $(\mathrm{Z})$ of the famous economist E. Altman is widely used to assess the financial condition and investment rating of an enterprise [2]. The DuPont model is also worth noting, which allows determining indicators changing profitability as a key factor of investment attractiveness [3]. An interesting approach is proposed by Dierkes, Maik; Erner, Carsten; Zeisberger, Stefan [4], who analyze a set of investment indicators based on probability distribution statistics study by repeatedly generating samples using the Monte Carlo method. The main internal factors of the enterprise investment attractiveness, represented through its financial condition, are studied in the works of G. Cokins, C. Walsh, J. C. Van Horne [5; 6; 7]. Russian researchers have also proposed several approaches to assessing the investment attractiveness of enterprises: based on indicators of financial and economic activity and competitiveness of the enterprise; by assessing the potential and risk of investment projects; based on the value assessment of the enterprise [8;9]. However, internal factors are the most manageable and informative for potential investors. According to E. Altman, G. Coins, C. Walsh $[2 ; 5 ; 6]$, the main internal factor of an enterprise's investment attractiveness is such a generalizing characteristic of its performance as the financial condition of the enterprise. The traditional tool for assessing the investment attractiveness of an enterprise based on this factor is the analysis of its proportions (coefficients) on the basis of financial statements $[10 ; 11 ; 12]$. Researchers [13;14] emphasized that the investment attractiveness of an enterprise is largely determined by the state of assets and financial risks of losing these assets. Therefore, the purpose of this study is to assess the financial risks of an enterprise based on the integrated assessment dynamic model of enterprise financial risks.

\section{METHODS}

In order to correct the investment strategy, the assessment of financial risks must contain reasonable reference points standards of the enterprise optimal state of financial and economic activity. The application of a dynamic model for assessing the financial risks of an enterprise, which contains reference criteria for high investment potential and low financial risk in accordance with the requirements of investors, is based on comparing the reference criteria with those achieved at the enterprise. The study used a comparison of the actual order of financial risk indicators with the one established in the reference dynamic model based on the Kendall rank correlation coefficient. It is proposed to use measures of dynamics of financial risk indicators - growth rates as a sign of ordering.

The reference "ideal" dynamic model for assessing the financial risks of an enterprise is an order of chain growth rates of indicators, the in the real activity of the enterprise ensures the reduction of financial risks [12]:

\section{$\mathrm{NP}>\mathrm{R}>$ ДК $>$ R $>$ OWC $>$ CA $>$ EC $>$ NA $>$ AR $>$ PGS $>$ LL $>$ AP $>$ SL}

Ordering comparison of the actual chain growth rates of financial risk indicators with the reference one is performed through a dynamic assessment of financial risks, which varies 
in the range from 0 to 1 and is calculated based on the value of the Kendall rank correlation coefficient:

$$
\tau=\frac{S}{n \frac{(n-1)}{2}}=\frac{2 S}{n(n-1)}
$$

where $\mathrm{n}$ is the number of indicators in the dynamic financial risk assessment model; $\mathrm{S}$ is the sum of the differences between the number of sequences and the number of inversions in the actual order of indicators; $\mathrm{S}=\mathrm{P}-\mathrm{Q}, \mathrm{P}$ is the total number of observations in the actual order following the current observations with a higher rank value, $\mathrm{Q}$ is the total number of observations in the actual order following the current observations with a lower rank value.

Ideally, the ordering of the actual chain growth rates of financial indicators should coincide with the reference dynamic model, and in this case the value of $\tau$ is equal to 1 , and the observed characteristics fully correspond to the interests of potential investors. The order of the actual indicators chain growth rates, completely opposite to the reference, gives a value of $\tau$ equal to zero. Therefore, the value of $\tau$, describing the approximation degree to the standard, is a generalizing measure of the investment attractiveness of the enterprise.

The modified formula of the Kendall rank correlation coefficient is the basis of the structural-dynamic integral assessment model of financial risk in the enterprise actual activity:

$$
\mathrm{SDAF}=\frac{\mathrm{M}(F, R)}{n(n-1)}=\frac{\sum_{i=1}^{n} \sum_{i=1}^{n} a_{i j}}{n(n-1)}
$$

where, SDAF is the structural and dynamic assessment of financial risk in the actual enterprise activity; $\mathrm{n}$ is the number of indicators - indicators of financial risk in the normative dynamic MIOR;

$\mathrm{M}(\mathrm{F}, \mathrm{N})$ is the amount of investment in the actual order of indicators - financial indicators $(\mathrm{F})$ in relation to regulatory (R);

$\mathrm{i}, \mathrm{j}$ are the ranks of $\mathrm{i}$-th and $\mathrm{j}$-th indicators - financial indicators in the regulatory order;

$a_{i j}$ is a variable that reflects the indicators presence or absence in the actual ordering - indicators of the "faster" ratio between $\mathrm{i}$ and $\mathrm{j}$ indicators - indicators, set by a MIOR $(\mathrm{i}=1, \ldots$, $n ; j=1, \ldots, n)$.

$a_{i j}$ indicator is defined with the formula:

$a_{i j}=\left\{\begin{array}{c}1, \text { if } r_{i}>r_{j} \text { with } i<j ; \\ u, \text { if } r_{i}<r_{j} \text { with } i>j ; \\ 0 \text { in other cases }\end{array}\right.$

where, $r_{i}$ and $r_{j}$ are ranks of $i-$ th an $j-$ th indicators financial risk indicators in actual order.

This rating varies between 0 and 1 . Moreover, the closer this estimate is to 1 , the more risky the situation will be for the company. The coincidence of the actual and the specified order of indicators - indicators of financial risk will indicate its reduction in the company's activities, while the $\mathrm{SDAF}=0$.

To test the model of structural - dynamic integrated assessment of financial risk, we used the chain financial indicators growth rates of the chemical industry enterprise from 2012 to 2019 , obtained from the financial statements (Table 1).

Table 1. Descriptive statistics of the used variables

\begin{tabular}{|c|c|c|c|c|c|c|}
\hline Variable & $\begin{array}{c}\text { Designati } \\
\text { on }\end{array}$ & Median & Average & $\begin{array}{c}\text { Standard } \\
\text { deviation }\end{array}$ & Min & Max \\
\hline Net profit growth rate & NP & 2,23 & 1,125 & 2,354 & 0,58 & 7,51 \\
\hline Revenue growth rate from products sales & R & 1,093 & 1,1 & 0,126 & 0,92 & 1,26 \\
\hline $\begin{array}{c}\text { Cash and short-term investments growth } \\
\text { rate }\end{array}$ & CSI & 3,425 & 1,125 & 5,030 & 0,08 & 14,5 \\
\hline Own working capital growth rate & OWC & 1,585 & 1,015 & 1,622 & 0,49 & 5,47 \\
\hline Current assets growth rate & CA & 1,198 & 1,07 & 0,495 & 0,76 & 2,28 \\
\hline Equity capital growth rate & EC & 1,321 & 1,29 & 0,311 & 0,97 & 1,98 \\
\hline Total assets growth rate & TA & 1,241 & 1,025 & 0,753 & 0,42 & 2,66 \\
\hline Non-current assets growth rate & NA & 0,888 & 0,935 & 0,416 & 0,02 & 1,46 \\
\hline Accounts receivable growth rate & AR & 1,415 & 0,85 & 1,115 & 0,49 & 3,77 \\
\hline The pace of growth stocks & PGS & 1,061 & 1,06 & 0,111 & 0,88 & 1,25 \\
\hline Long-term liabilities growth rate & LL & 0,741 & 0,69 & 0,300 & 0,39 & 1,31 \\
\hline Accounts payable growth rate & AP & 1,08 & 1,03 & 0,354 & 0,73 & 1,68 \\
\hline Short-term liabilities growth rate & SL & 1,13 & 0,85 & 0,568 & 0,76 & 2,41 \\
\hline
\end{tabular}


International Journal of Engineering Research and Technology. ISSN 0974-3154, Volume 13, Number 11 (2020), pp. 3579-3584

(C) International Research Publication House. https://dx.doi.org/10.37624/IJERT/13.11.2020.3579-3584

\section{RESULTS AND DISCUSSION}

Separately, for each year (from 2012 to 2019), based on the growth rates of financial indicators, a matrix of indicator preferences is built - indicators of financial risk and the actual order of their movement is determined. Table 2 shows an example of such a preference matrix for 2019.

Table 2. A complete matrix of preferences for actual indicators - indicators of financial risk by growth rate for 2019

\begin{tabular}{|c|c|c|c|c|c|c|c|c|c|c|c|c|c|c|c|c|}
\hline \multirow{2}{*}{ № } & \multirow{2}{*}{ Indicators } & 1 & 2 & 3 & 4 & 5 & 6 & 7 & 8 & 9 & 10 & 11 & 12 & 13 & \multirow{2}{*}{$\Sigma$} & \multirow{2}{*}{$r_{\phi}$} \\
\hline & & NP & $\mathrm{R}$ & CSI & OWC & $\mathrm{CA}$ & $\mathrm{EC}$ & TA & NA & $\mathrm{AR}$ & PGS & LL & $\mathrm{AP}$ & SL & & \\
\hline 1 & NP & & -1 & 1 & -1 & -1 & -1 & -1 & -1 & -1 & -1 & -1 & -1 & -1 & -10 & 12 \\
\hline 2 & $\mathrm{R}$ & 1 & & 1 & 1 & 1 & -1 & -1 & -1 & -1 & -1 & -1 & 1 & 1 & 0 & 7 \\
\hline 3 & CSI & -1 & -1 & & -1 & -1 & -1 & -1 & -1 & -1 & -1 & -1 & -1 & -1 & -12 & 13 \\
\hline 4 & OWC & 1 & -1 & 1 & & -1 & -1 & -1 & -1 & -1 & -1 & -1 & 1 & -1 & -6 & 10 \\
\hline 5 & $\mathrm{CA}$ & 1 & -1 & 1 & 1 & & -1 & -1 & -1 & -1 & -1 & -1 & 1 & -1 & -4 & 9 \\
\hline 6 & $\mathrm{EC}$ & 1 & 1 & 1 & 1 & 1 & & -1 & -1 & 1 & -1 & -1 & 1 & 1 & 4 & 5 \\
\hline 7 & TA & 1 & 1 & 1 & 1 & 1 & 1 & & 1 & 1 & 1 & 1 & 1 & 1 & 12 & 1 \\
\hline 8 & NA & 1 & 1 & 1 & 1 & 1 & 1 & -1 & & 1 & 1 & -1 & 1 & 1 & 8 & 3 \\
\hline 9 & $\mathrm{AR}$ & 1 & 1 & 1 & 1 & 1 & -1 & -1 & -1 & & -1 & -1 & 1 & 1 & 2 & 6 \\
\hline 10 & PGS & 1 & 1 & 1 & 1 & 1 & 1 & -1 & -1 & 1 & & -1 & 1 & 1 & 6 & 4 \\
\hline 11 & LL & 1 & 1 & 1 & 1 & 1 & 1 & -1 & 1 & 1 & 1 & & 1 & 1 & 10 & 2 \\
\hline 12 & AP & 1 & -1 & 1 & -1 & -1 & -1 & -1 & -1 & -1 & -1 & -1 & & -1 & -8 & 11 \\
\hline 13 & SL & 1 & -1 & 1 & 1 & 1 & -1 & -1 & -1 & -1 & -1 & -1 & 1 & & -2 & 8 \\
\hline
\end{tabular}

As can be seen from Table 2, aggregate assets, long-term liabilities and non-current assets received preferences in growth rates. This indicates that the company has increased its non-current capital and borrowed funds.
Table 3 shows the calculation of the inversions number for the growth rate of each financial indicator in comparison with the reference order and the structural and dynamic assessment of the financial risk level of the enterprise in 2019.

Table 3. Calculation of the financial risk level structural and dynamic assessment of PAO Kazanorgsintez for 2019

\begin{tabular}{|c|c|c|c|c|c|c|c|c|c|c|c|c|c|c|c|}
\hline \multirow{2}{*}{ № } & \multirow{2}{*}{ Indicators } & 1 & 2 & 3 & 4 & 5 & 6 & 7 & 8 & 9 & 10 & 11 & 12 & 13 & \multirow{2}{*}{$\begin{array}{l}\text { m- number } \\
\text { of } \\
\text { inversions }\end{array}$} \\
\hline & & NP & $\mathrm{R}$ & CSI & OWC & CA & $\mathrm{EC}$ & TA & NA & $\mathrm{AR}$ & PGS & $\mathrm{LL}$ & $\mathrm{AP}$ & $\mathrm{SL}$ & \\
\hline 1 & $\mathrm{NP}$ & & 1 & 0 & 1 & 1 & 1 & 1 & 1 & 1 & 1 & 1 & 1 & 1 & 11 \\
\hline 2 & $\mathrm{R}$ & 1 & & 0 & 0 & 0 & 1 & 1 & 1 & 1 & 1 & 1 & 0 & 0 & 7 \\
\hline 3 & CSI & 0 & 0 & & 1 & 1 & 1 & 1 & 1 & 1 & 1 & 1 & 1 & 1 & 10 \\
\hline 4 & OWC & 1 & 0 & 1 & & 1 & 1 & 1 & 1 & 1 & 1 & 1 & 0 & 1 & 10 \\
\hline 5 & $\mathrm{CA}$ & 1 & 0 & 1 & 1 & & 1 & 1 & 1 & 1 & 1 & 1 & 0 & 1 & 10 \\
\hline 6 & $\mathrm{EC}$ & 1 & 1 & 1 & 1 & 1 & & 1 & 1 & 0 & 1 & 1 & 0 & 0 & 9 \\
\hline 7 & TA & 1 & 1 & 1 & 1 & 1 & 1 & & 0 & 0 & 0 & 0 & 0 & 0 & 6 \\
\hline 8 & NA & 1 & 1 & 1 & 1 & 1 & 1 & 0 & & 0 & 0 & 1 & 0 & 0 & 7 \\
\hline 9 & $\mathrm{AR}$ & 1 & 1 & 1 & 1 & 1 & 0 & 0 & 0 & & 1 & 1 & 0 & 0 & 7 \\
\hline 10 & PGS & 1 & 1 & 1 & 1 & 1 & 1 & 0 & 0 & 1 & & 1 & 0 & 0 & 8 \\
\hline 11 & LL & 1 & 1 & 1 & 1 & 1 & 1 & 0 & 1 & 1 & 1 & & 0 & 0 & 9 \\
\hline 12 & AP & 1 & 0 & 1 & 0 & 0 & 0 & 0 & 0 & 0 & 0 & 0 & & 1 & 3 \\
\hline 13 & SL & 1 & 0 & 1 & 1 & 1 & 0 & 0 & 0 & 0 & 0 & 0 & 1 & & 5 \\
\hline \multicolumn{15}{|c|}{ Sum of $\mathrm{m}$ for i - M $(\mathrm{F}, \mathrm{R})$} & 102 \\
\hline \multicolumn{15}{|c|}{$\mathrm{n}$ - number of indicators in the MIOR } & 13 \\
\hline \multicolumn{15}{|c|}{ SDAF } & 0,6538 \\
\hline
\end{tabular}


International Journal of Engineering Research and Technology. ISSN 0974-3154, Volume 13, Number 11 (2020), pp. 3579-3584

(C) International Research Publication House. https://dx.doi.org/10.37624/IJERT/13.11.2020.3579-3584

The largest number of inversions is observed in the growth rates of net profit, cash and short-term investments, own working capital, and current assets. This indicates that the company in 2019 reduced the growth rate of liquidity, which was reflected in a decrease in working capital and net profit.
Table 4 shows the actual rank of indicators - indicators of financial risk and the indicator dynamics of the structural and dynamic level assessment of enterprise financial risk.

Table 4. Actual rank of financial risk indicators and dynamics of structural and dynamic assessment of the financial risk level

\begin{tabular}{|c|c|c|c|c|c|c|c|c|c|}
\hline \multirow{2}{*}{ Indicators } & \multirow{2}{*}{ Regulatory rank } & \multicolumn{8}{|c|}{ The actual rank of traffic indicators - risk indicators } \\
\hline & & 2012 & 2013 & 2014 & 2015 & 2016 & 2017 & 2018 & 2019 \\
\hline NP & 1 & 1 & 12 & 2 & 3 & 9 & 7 & 2 & 12 \\
\hline $\mathrm{R}$ & 2 & 5 & 5 & 10 & 7 & 7 & 5 & 6 & 7 \\
\hline CSI & 3 & 2 & 9 & 1 & 1 & 13 & 4 & 3 & 13 \\
\hline OWC & 4 & 12 & 13 & 7 & 2 & 2 & 10 & 4 & 10 \\
\hline $\mathrm{CA}$ & 5 & 6 & 6 & 4 & 6 & 5 & 9 & 7 & 9 \\
\hline $\mathrm{EC}$ & 6 & 3 & 2 & 8 & 4 & 3 & 3 & 5 & 5 \\
\hline TA & 7 & 9 & 7 & 9 & 11 & 6 & 1 & 13 & 1 \\
\hline NA & 8 & 10 & 8 & 12 & 13 & 8 & 11 & 1 & 3 \\
\hline AR & 9 & 11 & 11 & 5 & 5 & 1 & 12 & 12 & 6 \\
\hline PGS & 10 & 8 & 3 & 11 & 8 & 4 & 6 & 8 & 4 \\
\hline LL & 11 & 13 & 10 & 13 & 12 & 12 & 13 & 9 & 2 \\
\hline AP & 12 & 7 & 4 & 6 & 9 & 10 & 2 & 11 & 11 \\
\hline $\mathrm{SL}$ & 13 & 4 & 1 & 3 & 10 & 11 & 8 & 10 & 8 \\
\hline & & 0,346 & 0,6410 & 0,3846 & 0,2564 & 0,4487 & 0,4487 & 0,2692 & 0,6538 \\
\hline
\end{tabular}

The dynamics of the structural and dynamic assessment integral indicator of the financial risk level in Figure 1 demonstrates the unstable financial position of the enterprise.

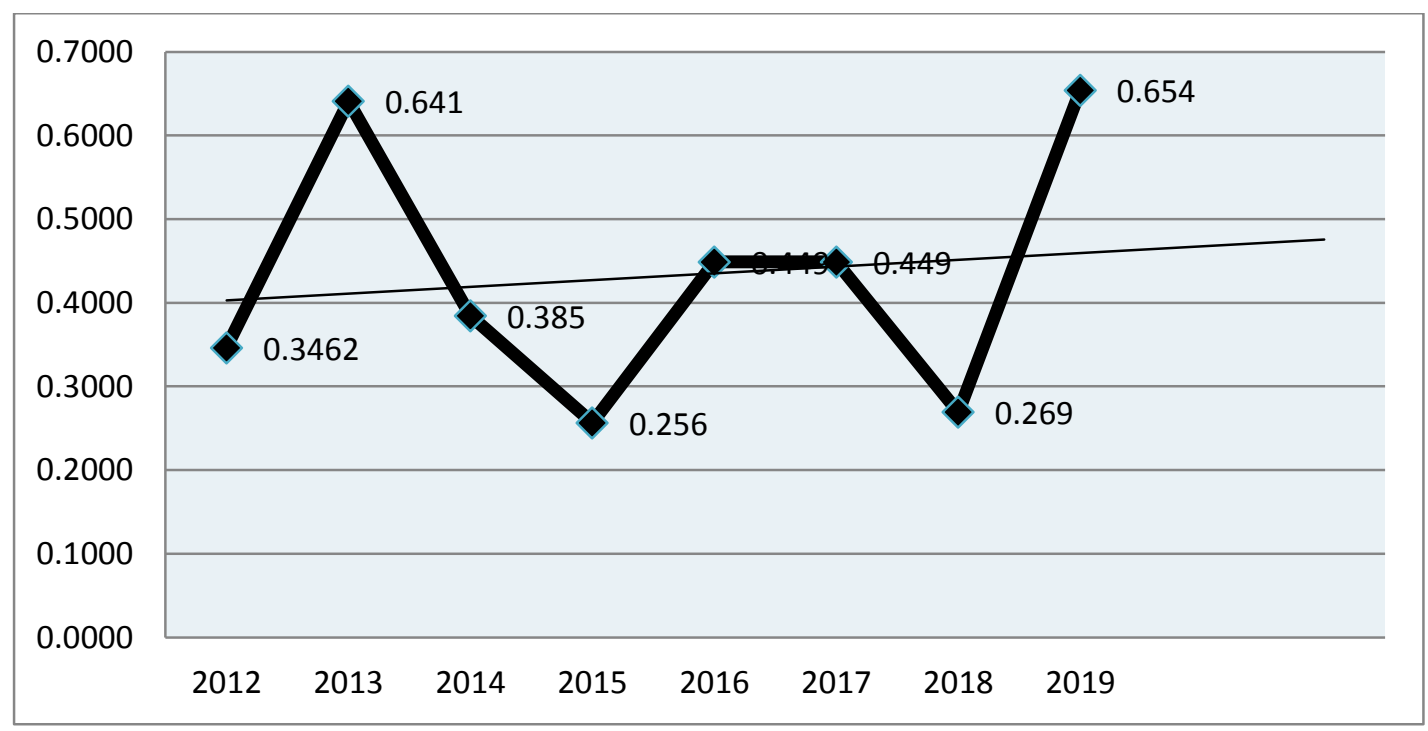

Fig. 1. Dynamics of the structural and dynamic integral indicator assessment of the financial risk level of the enterprise 


\section{SUMMARY}

In general, the dynamic assessment of the enterprise financial risk level is quite volatile. Low ranks of net profit growth rates, cash and short-term investments, own working capital, current assets, accounts payable are observed in 2013, 2016 and 2019. The growth of total assets, long-term liabilities and non-current assets in 2019 did not allow achieving compliance with the benchmark indicators of investment attractiveness in terms of low financial risks. However, the continued growth of non-current assets, equity and revenue since 2018 are indicators of the potential growth of the company's investment attractiveness.

\section{CONCLUSIONS}

The study tested a model of structural - dynamic assessment of enterprise financial risk, systematized a wide variety of indicators, has given a vivid presentation of economic information in the result ordinal measure of connection between dynamically ordered indicators, in conformity with the revealed preference relations. Dynamic assessment of the enterprise financial risk level is quite volatile. This may negatively affect the investment attractiveness of the company. It is possible to predict high risks of investing in this enterprise. The results of the study indicate the need to develop a set of measures for the owners of the enterprise to reduce financial risks and achieve stable growth of investment attractiveness.

It is possible to highlight the following advantages of the enterprise financial risks dynamic assessment model based on applied statistical analysis of indicators that characterize the internal environment of the enterprise:

- systematization of heterogeneous quantitative indicators of investment attractiveness based on the analysis and selection of its significant factors using open and accessible information to potential investors;

- ensuring the ability to reflect the priorities and views of the investor-analyst in the process of measuring and evaluating investment attractiveness;

- use of generally accepted judgments about the need to increase investment attractiveness and its defining indicators in the long term;

- providing a cardinal measurement of the connection between dynamically ordered indicators of investment attractiveness in the process of its measurement and evaluation;

- ensuring consistency, comparability and methodological unity of approaches to measuring and evaluating the investment attractiveness of an enterprise.

\section{ACKNOWLEDGEMENTS}

The work is performed according to the Russian Government Program of Competitive Growth of Kazan Federal University.

\section{REFERENCES}

[1] Yakupova N, Levachkova S, Iskhakova G, Kadochnikova E, Lelyuk A. Integral assessment of the enterprise investment attractiveness: Testing the hypothesis of non-conformity to investor's interests. SCOPUS1816949X-2017-12-19-SID85030456612. 2017 Jan 1.

[2] Altman EI. Financial ratios, discriminant analysis and the prediction of corporate bankruptcy. The journal of finance. 1968 Sep 1;23(4):589-609.

[3] Rogova E. Dupont analysis of the efficiency and investment appeal of russian oil-extracting companies. In8th International Scientific Conference "Business and Management 2014 May 14.

[4] Dierkes M, Erner C, Zeisberger S. Investment horizon and the attractiveness of investment strategies: A behavioral approach. Journal of Banking \& Finance. 2010 May 1;34(5):1032-46.

[5] Walsh C. Key management ratios: the 100+ ratios every manager needs to know. Pearson Education; 2008.

[6] Cokins G. Performance management: Integrating strategy execution, methodologies, risk, and analytics. John Wiley \& Sons; 2009 Mar 17.

[7] Van Horne JC. Fundamentals of financial management. Prentice Hall, 1022 p, 2009.

[8] Yakupov NM, Salahieva MF, Kadochnikova EI, Lelyukh AV, Kvon GM. Peculiarities of modelling of the enterprise investment attractiveness in the conditions of multicollinearity of predictors. Journal of Engineering and Applied Sciences. 2017;12(19):4922-6.

[9] Veselovsky M, Sikyr M, Askerov P, Gnezdova J, Abrashkin M. Development features, financing methods and investment attractiveness evaluation of start-ups in russia. InThe 10th International Days of Statistics and Economics: Conference proceedings 2016 Sep 8 (pp. 1948-1957).

[10] Khasanova AS, Kvon GM, Yakupova NM, Khamidullin FF, Samysheva EY. Assessment of efficiency of capital investment project implementation of resource-saving technology for the real sector of the economy in Tatarstan Republic. Mediterranean Journal of Social Sciences. 2015 Mar 26;6(2 S3):155-161.

[11] Kvon GM, Lushchik IV, Karpenko MA, Zaitseva NA, Kulkov AA, Galushkin AA, Yakupova NM. Regional investment policy: analysis and assessment of the investment environment state. Eurasian Journal of Analytical Chemistry. 2017 Jan 1;12(5):835-53.

[12] Safiullin AR, Gubaidullina AI. Approach To Risk And Investment Attractiveness Estimation For Regional Economic Activity Of Russia. International Transaction Journal Of Engineering Management \& Applied Sciences \& Technologies. 2018 Nov 9;9(5):455-67. 
International Journal of Engineering Research and Technology. ISSN 0974-3154, Volume 13, Number 11 (2020), pp. 3579-3584

(C) International Research Publication House. https://dx.doi.org/10.37624/IJERT/13.11.2020.3579-3584

[13] Beilin IL, Khomenko VV, Yakupova NM, Kadochnikova EI. Modeling of economic effects of commercialization of high-tech developments at small innovative enterprises of polymer profile. Journal of Social Sciences Research, 2018;5:188-193.

[14] Kadochnikova E, Semenikhina N, Garifullina A. Econometric assessment of the factors of enterprise receivables. SCOPUS09758364-2019-10-2SID85074630095. 2019 Jan 1.

[15] Valz PD, McLeod AI. A simplified derivation of the variance of Kendall's rank correlation coefficient. The American Statistician. 1990 Feb 1;44(1):39-40

[16] Bottcher HF, Posthoff C. Mathematical treatment of rank correlation-comparative observation on Kendall and spearman coefficients. Zeitschrift fur psychologie. 1975 Jan 1;183(2):201-17. 